\title{
Editorial
}

\section{Beyond Hypertension and Cardio-Renal Syndrome: The Need to Acknowledge and Incorporate Renal Disease in Cardiac Electrophysiology Trials}

\author{
Luke J. Laffin ${ }^{a}$ Marion A. Hofmann-Bowman ${ }^{b}$ \\ a Department of Medicine, Section of Cardiology, University of Chicago Medicine, Chicago, IL, USA; \\ ${ }^{b}$ Department of Medicine, Section of Cardiology, University of Michigan, Ann Arbor, MI, USA
}

Increasingly, but still insufficiently, cardiologists recognize the increased risk of death associated with comorbid conditions such as chronic kidney disease (CKD) and diabetes mellitus. While maintaining appropriate blood glucose levels and arresting the progression of renal disease are important treatment goals in these patients, a majority of patients are intensely affected by and die of cardiovascular $(\mathrm{CV})$ disease.

In this issue of the American Journal of Nephrology, Airy and colleagues analyze health care records of over 62,00 patients with at least stage 3 CKD that were nondialysis dependent. With a median follow-up of 4 years, the authors find that the presence of atrial fibrillation (in 6,639 patients, $10.6 \%$ of the cohort) was associated with a $23 \%$ higher risk of all-cause mortality and a $45 \%$ higher risk of CV mortality [1].

The above findings are important in that they confirm the findings of prior studies demonstrating the excess mortality that atrial fibrillation portends in CKD patients. Importantly, the study provides incremental novel findings by linking the Electronic Health Record-based CKD registry at the Cleveland Clinic with the Ohio Department of Health mortality data. This provides specific information as to the cause of death grouped into (i) CV death, (ii) malignancy related death, and (iii) non-CV and non-malignancy-related death. Multivariable analysis showed atrial fibrillation to be associated with a significantly increased risk of mortality (adjusted HR 1.23, 95\% CI 1.18-1.29) with $49 \%$ of all deaths due to CV diseases. Among CV causes of death, atrial fibrillation had an increased risk of death from heart failure (HR 1.58, 95\% CI 1.25-1.98) compared to cerebrovascular disease (HR $1.31,95 \%$ CI 1.06-1.61) and ischemic heart disease (HR $1.21,95 \%$ CI 1.09-1.34). It is important to point out that the excess risk for $\mathrm{CV}$ mortality in CKD patients with atrial fibrillation was seen across the spectrum of CV diseases, and not just death from stroke/cerebrovascular disease.

A second interesting finding of this large single-center cohort study is that CKD stage 4 is an independent risk factor for atrial fibrillation and as such can be added to the list of validated risk factors for atrial fibrillation, 
namely, age, diabetes, hypertension, male sex, African American race, coronary artery disease, congestive heart failure, and valvular heart disease.

However, this and other studies raise the following questions: Why do we observe this excess of CV mortality among patients with atrial fibrillation and CKD? Is atrial fibrillation a marker for more advanced CV disease? Are the metabolic and electrolyte abnormalities seen in CKD more pronounced or detrimental in those with atrial fibrillation? And finally, perhaps more provocatively, could the treatment paradigms commonly used to treat atrial fibrillation, that is, rate or rhythm control together with anticoagulation, be ineffective, or even detrimental, to those patients with CKD?

The answers to the first 2 questions are likely yes. Mechanistically, it is conceivable that cardiac fibrosis, left ventricular hypertrophy, ischemia, autonomic imbalance, and rapid fluid and electrolyte shifts commonly associated with kidney disease predispose patients to cardiac arrhythmia and myocardial dysfunction. However, for the third question, the answer is unknown. This is unknown, not only because the majority of clinical trials of atrial fibrillation management include a limited share of patients with renal disease but also because we oftentimes have no idea of the proportion of patients with $\mathrm{CKD}$ enrolled in these trials.

A prime example is the highly touted CASTLE-AF trial published earlier this year [2]. CASTLE-AF suggests that catheter ablation for symptomatic atrial fibrillation in patients with heart failure is superior to medical therapy with regard to the primary endpoint, which was the composite of all-cause mortality and unplanned hospitalization for worsening heart failure. Among this cohort with substantial proportions of hypertension, obesity, and diabetes, there is no mention of renal function in the manuscript or in the supplement. The only note in the trial's entry criteria is that patients on dialysis should not be enrolled. Perhaps future publications from this cohort will better delineate if any patients with CKD were enrolled, and if their outcomes differed from those seen in the population without renal disease. However, until then, we should not assume that CKD patients, at least the group with more advanced CKD, will behave similarly to those in the trial. Until we have more data on outcomes, catheter ablation for atrial fibrillation in CKD and ESRD patients should be reserved for very selected and individualized situations [3].

Unfortunately, early hallmark trials of atrial fibrillation management strategies similarly lack acknowledgement and comment on the proportion of participants with CKD (Table 1). The 2 most prominent trials of rate versus rhythm control in atrial fibrillation are AFFIRM and RACE. Although AFFIRM made clear its exclusion of dialysis patients, neither trial reported baseline renal function nor did either report results stratified by degree of renal disease. The only significant prospective cohort analysis of $\mathrm{CKD}$ and atrial fibrillation, comparing a rate versus rhythm control strategy, was performed using the GUSTO-III data, a post-myocardial infarction population [4]. In all, 413 patients with atrial fibrillation and CKD were compared to 559 patients with atrial fibrillation and normal renal function. It was found that CKD did not significantly impact the relationship between rate controlling agents (beta blocker, calcium channel blocker, or digitalis) versus antiarrhythmic agents (primarily consisted of amiodarone, procainamide, and sotalol accounting for $80 \%$ of antiarrhythmic drug use) and 30-day and 1-year mortality outcome. However, confirmatory larger and prospectively randomized clinical trials are needed to address the role of the rate or rhythm controlling agents in patients with atrial fibrillation and $\mathrm{CKD}$, since evidence from clinical trials on rate and rhythm control strategies in atrial fibrillation may not be generalizable to patients with impaired renal function.

The recent trials of direct oral anti-coagulants for thromboembolism prophylaxis in atrial fibrillation are far better with respect to their inclusion of patients with Stage $3 \mathrm{CKD}$, but again limited data exist among patients with more advanced renal disease (Table 1).

This shortage of robust randomized control trial data ultimately leads to heterogeneous practice patterns in patients with CKD and atrial fibrillation [5]. One must hope that future pivotal trials, such as the soon to be published Catheter Ablation vs. Anti-arrhythmic Drug Therapy for Atrial Fibrillation Trial (CABANA, clinicaltrials.gov NCT00911508), will at the very least include data regarding baseline renal function and the percentage of patients enrolled with CKD.

Looking beyond atrial fibrillation, lack of CKD acknowledgement and inclusion is seen in other seminal electrophysiology clinical trials of implantable cardioverter-defibrillators (ICDs) for primary prevention of sudden cardiac death and cardiac resynchronization therapy (Table 1.) The European Heart Rhythm Association published a comprehensive position statement on decision-making in patients with $\mathrm{CKD}$ and cardiac rhythm disturbances or implantable electrical devices in 2015 [3]. It provides guidance for this unique patient group but is limited due to the imperfect data available 
Table 1. Selection of landmark electrophysiology randomized control trials and participant CKD information

\begin{tabular}{|c|c|c|c|c|c|}
\hline Intervention & Trial name & Year & $\begin{array}{l}\text { Baseline kidney } \\
\text { function }\end{array}$ & $\begin{array}{l}\text { Exclusion } \\
\text { criteria }\end{array}$ & $\begin{array}{l}\text { Percentage of } \\
\text { patients enrolled } \\
\text { with CKD }\end{array}$ \\
\hline $\begin{array}{l}\text { Rate vs. rhythm control } \\
\text { in atrial fibrillation }\end{array}$ & RACE & 2002 & Not reported & Not stated & Unknown \\
\hline \multirow[t]{2}{*}{$\begin{array}{l}\text { Direct oral } \\
\text { anticoagulants } \\
\text { in atrial fibrillation }\end{array}$} & $\begin{array}{l}\text { RE-LY } \\
\text { (dabigatran) }\end{array}$ & 2009 & Not reported & $\mathrm{CrCl}<30 \mathrm{~mL} / \mathrm{min}$ & $\begin{array}{l}\mathrm{CrCl}<50 \mathrm{~mL} / \mathrm{min} \text {, } \\
19 \% \text { of total } \\
\text { enrollment }\end{array}$ \\
\hline & $\begin{array}{l}\text { ROCKET AF } \\
\text { (rivaroxaban) }\end{array}$ & 2011 & $\begin{array}{l}\text { Mean } \mathrm{CrCl} \text { of } \\
67 \mathrm{~mL} / \mathrm{min} \text {, } \\
\text { IQR } 52-87\end{array}$ & $\mathrm{CrCl}<30 \mathrm{~mL} / \mathrm{min}$ & $\begin{array}{l}\mathrm{CrCl}<50 \mathrm{~mL} / \mathrm{min} \text {, } \\
21 \% \text { of total } \\
\text { enrollment }\end{array}$ \\
\hline \multirow[t]{2}{*}{$\begin{array}{l}\text { Catheter ablation for } \\
\text { atrial fibrillation }\end{array}$} & CASTLE-AF & 2018 & Not reported & $\begin{array}{l}\text { Dialysis } \\
\text { dependance }\end{array}$ & Unknown \\
\hline & CABANA & Likely 2018 & Pending & Pending & Pending \\
\hline \multirow[t]{2}{*}{$\begin{array}{l}\text { ICD for primary } \\
\text { prevention of SCD }\end{array}$} & DANISH & 2016 & $\begin{array}{l}\text { Mean eGFR } \\
73 \mathrm{~mL} / \mathrm{min} / 1.73 \mathrm{~m}^{2} \\
\text { IQR of } 58-92\end{array}$ & $\begin{array}{l}\text { Dialysis } \\
\text { dependance }\end{array}$ & $\begin{array}{l}\mathrm{eGFR}<73 \mathrm{~mL} / \mathrm{min} / \\
1.73 \mathrm{~m}^{2}, 49 \% \text { of } \\
\text { total enrollment }\end{array}$ \\
\hline & SCD-HeFT & 2005 & $\begin{array}{l}\text { Mean serum Cr } \\
\text { of } 1.1 \mathrm{mg} / \mathrm{dL} \text {, } \\
\text { IQR of } 0.9-1.4\end{array}$ & $\mathrm{Cr}>2.5 \mathrm{mg} / \mathrm{dL}$ & Unknown \\
\hline
\end{tabular}

$\mathrm{CrCl}$, creatinine clearance; $\mathrm{CKD}$, chronic kidney disease; IQR, interquartile range; eGFR, estimated glomerular filtration rate; Cr, creatinine; ICD, implantable cardioverter defibrillator; SCD, sudden cardiac death.

(predominantly registry cohorts and meta-analyses) in patients with CKD and cardiac rhythm disturbances.

A recently published observational study of 5,877 community-based patients with heart failure with reduced ejection fraction and CKD demonstrates that ICD placement was not significantly associated with improved survival but was associated with increased risk for subsequent hospitalization due to heart failure and all-cause hospitalization with mean follow-up of 3.1 years [6]. ICDs have known complications (ICD device infection, worsening Tricuspid regurgitation from RV lead) that potentially may contribute to higher rates of hospitalization overall. A 2014 meta-analysis similarly demonstrated that among patients with an estimated glomerular filtration rate $<60 / \mathrm{min} / 1.73 \mathrm{~m}^{2}$, no survival benefit is seen with primary prevention ICDs [7]. These analyses are clear examples why certain electrophysiology interventions may not provide benefit, and in fact may be harmful, to patients with CKD. They also suggest that we must study this high-risk group more extensively. Specific data 
on patient outcome and device performance of subcutaneous ICDs are awaited from the EFFORTLESS S-ICD registry, in which CKD was present in $9 \%$ of the patients implanted with subcutaneous ICD [8].

Rather than being discouraged by the apparent apathy toward CKD in certain cardiac electrophysiology clinical trials, this should be viewed as an opportunity for increased collaboration among CV and renal clinical trialists. What can begin with retrospective analyses of the pivotal atrial fibrillation trials, with an eye toward possi- ble CKD subgroups, will hopefully result in future cardiac electrophysiology trials incorporating and reporting outcomes in patients with Stage 3 CKD or higher.

\section{Disclosure Statement}

Dr. Luke Laffin is supported by the NHLBI T32 postdoctoral training grant (T32 HL007381). Dr. Luke Laffin and Dr. Marion A. Hofmann-Bowman have no conflicts of interest to disclose.

\section{References}

1 Airy M, Schold J, Jolly S, Arrigain S, Bansal N, Winkelmayer W, et al: Cause-specific mortality in patients with chronic kidney disease and atrial fibrillation. Am J Nephrol 2018;48:3645.

2 Marrouche NF, Brachmann J, Andresen D, Siebels J, Boersma L, Jordaens L, et al: Catheter ablation for atrial fibrillation with heart failure. N Engl J Med 2018;378:417427.

3 Boriani G, Savelieva I, Dan GA, Deharo JC, Ferro C, Israel CW, et al: Chronic kidney disease in patients with cardiac rhythm disturbances or implantable electrical devices: clinical significance and implications for decision making-a position paper of the European heart rhythm association endorsed by the heart rhythm society and the Asia Pacific heart rhythm society. Europace 2015;17: 1169-1196.

4 Williams ES, Thompson VP, Chiswell KE, Alexander JH, White HD, Ohman EM, et al: Rate versus rhythm control and outcomes in patients with atrial fibrillation and chronic kidney disease: data from the GUSTO-III trial. Cardiol J 2013;20:439-446.

5 Potpara TS, Lenarczyk R, Larsen TB, Deharo JC, Chen J, Dagres N, et al: Management of atrial fibrillation in patients with chronic kidney disease in Europe results of the European heart rhythm association survey. Europace 2015;17:1862-1867.

6 Bansal N, Szpiro A, Reynolds K, Smith DH, Magid DJ, Gurwitz JH, et al: Long-term out- comes associated with implantable cardioverter defibrillator in adults with chronic kidney disease. JAMA Intern Med 2018;178:390398.

7 Pun PH, Al-Khatib SM, Han JY, Edwards R, Bardy GH, Bigger JT, et al: Implantable cardioverter-defibrillators for primary prevention of sudden cardiac death in CKD: a meta-analysis of patient-level data from 3 randomized trials. Am J Kidney Dis 2014;64: 32-39.

8 Boersma L, Barr C, Knops R, Theuns D, Eckardt L, Neuzil P, et al: Implant and midterm outcomes of the subcutaneous implantable cardioverter-defibrillator registry: the EFFORTLESS study. J Am Coll Cardiol 2017;70: 830-841. 